\title{
A Detailed Comparison Between FOC and DTC Methods of a Permanent Magnet Synchronous Motor Drive
}

\author{
Navid Maleki ${ }^{1, *}$, Mohammad Reza Alizadeh Pahlavani ${ }^{2}$ Iman Soltani \\ ${ }^{1}$ Department of Electrical Engineering, Saveh Branch, Islamic Azad University, Saveh, Iran \\ ${ }^{2}$ Faculty of Electrical Engineering, Malek-Ashtar University of Technology (MUT), Tehran, Iran
}

Email address:

NavidMaleki86@yahoo.ca (N. Maleki), MR_Alizadehp@iust.ac.ir(M. R. Alizadeh), i_soltani@ikiu.ac.ir (I. Soltani)

\section{To cite this article:}

Navid Maleki, Mohammad Reza Alizadeh Pahlavani, Iman Soltani. A Detailed Comparison Between FOC and DTC Methods of a Permanent Magnet Synchronous Motor Drive. Journal of Electrical and Electronic Engineering. Special Issue: Research and Practices in Electrical and Electronic Engineering in Developing Countries. Vol. 3, No. 2-1, 2015, pp. 92-100. doi: 10.11648/j.jeee.s.2015030201.30

\begin{abstract}
This paper focuses on detail comparison between two common control methods including Field Oriented Control (FOC) and Direct Torque Control (DTC) of the Permanent Magnet Synchronous (PMS) motor. The main characteristics of the motor such as torque, flux and speed under different operation conditions are studied and the advantages of FOC and DTC are obtained. It can be concluded that although both the DTC and FOC methods have different structures but the motor has the same behavior on the control methods. Thus, it is concluded that both the methods can be implemented as the Direct Flux Ccontrol (DFC) and can be applied as an optimized method of PMS motor control in the industry applications.
\end{abstract}

Keywords: PMSM, Vector Control (VC), FOC, DTC, Optimized Control Method

\section{Introduction}

In the recent years, domain of PMSM's applications in different industries such as electricity, gas, oil, transportation, military and etc. have been developed because of their two natural specifications. In the most of variable speed industrial applications, high power density, higher rigidity, lower volume, low inertia and high efficiency compared to DC and induction motors, are superiority indices of these motors. Discovery of new magnets have been a great help in development of designing and producing process of these kinds of motors in the world of industry. These kinds of magnetic materials have very high energy and resistance against demagnetizing property and this is resulted that new generation motors have lower volume compared to past common motors which took more spaces because they used Ferrite magnets or Aluminum Nickel Cobalt (AlNiCo) [1].

The optimized control of these motors to promote effectiveness and efficiency in the industry is something necessary and inevitable. In this way in his paper by studying control methods of synchronous permanent magnet motors such as FOC and DTC [4-9], and optimized control method is proposed to control a PMSM with capability of using in the industry.

This paper focuses on detail comparison between two common control methods including Field Oriented Control (FOC) and Direct Torque Control (DTC) of the Permanent Magnet Synchronous (PMS) motor. The main characteristics of the motor such as torque, flux and speed under different operation conditions studied and the advantages of FOC and DTC are obtained. It can be concluded that although both the DTC and FOC methods have different structures but the motor has the same behavior on the control methods. Thus, it is deduced that both the methods can be implemented as the Direct Flux Control (DFC) and can be applied as an optimized method of PMS motor control in the industry applications.

\section{Dynamic Modeling of Motor}

Dynamic model of PMSM in the rotational two phase system $\mathrm{d}-\mathrm{q}$ in the steady state is achieved:

$$
\begin{gathered}
v_{d}=R_{s} i_{d}+\frac{d \Psi_{d}}{d t}-\omega_{e} \Psi_{q} \\
v_{q}=R_{s} i_{q}+\frac{d \Psi_{q}}{d t}+\omega_{e} \Psi_{d} \\
\Psi_{d}=L_{d} i_{d}+L_{m d} i_{D}+\Psi_{f} \\
\Psi_{q}=L_{q} i_{q}+L_{m q} i_{Q}
\end{gathered}
$$




$$
\begin{gathered}
T_{e}=\frac{3}{2} \frac{p}{2}\left[\Psi_{f} i_{q}+\left(L_{d}-L_{q}\right) i_{d} i_{q}\right] \\
\frac{p}{2}\left(T_{e}-T_{L}\right)=J \frac{d \omega_{r}}{d t}
\end{gathered}
$$

Presentation of flux vector of machine in respect with reference frame of rotor is showed in "Fig. 1".

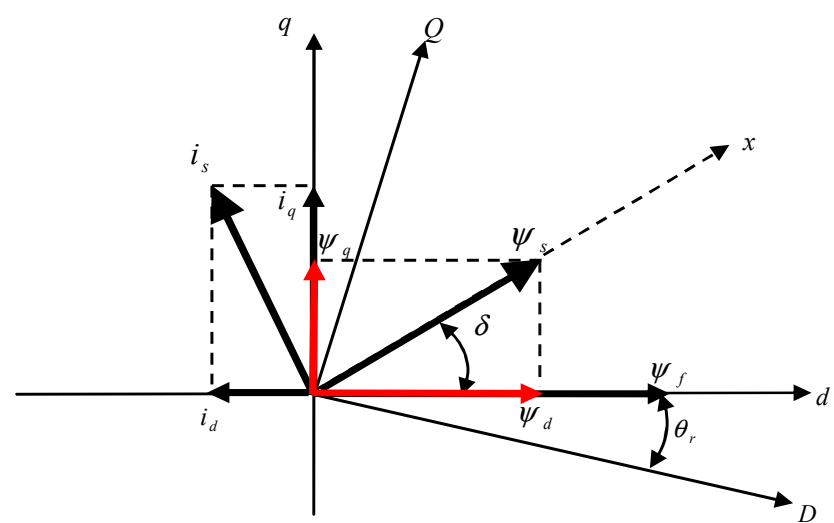

Figure 1. Flux vector in static D-Q system and rotational d-q system [2]

\section{Vector Control Based on Stator Flux Reference Frame}

In the method, real axe of $\mathrm{x}-\mathrm{y}$ system is along with stator flux vector and control is accomplished along with field "Fig. 2". Current variables, based on (7) and (8) can be transformed from rotational rotor system to reference stator flux system and vice versa and electromagnetic torque relation in the $x-y$ stator system is calculated by (9).

$$
\begin{gathered}
{\left[\begin{array}{l}
i_{x} \\
i_{y}
\end{array}\right]=\left[\begin{array}{cc}
\cos \delta & \sin \delta \\
-\sin \delta & \cos \delta
\end{array}\right]\left[\begin{array}{l}
i_{d} \\
i_{q}
\end{array}\right]} \\
{\left[\begin{array}{l}
i_{d} \\
i_{q}
\end{array}\right]=\left[\begin{array}{cc}
\cos \delta & -\sin \delta \\
\sin \delta & \cos \delta
\end{array}\right]\left[\begin{array}{l}
\mathrm{i}_{\mathrm{x}} \\
\mathrm{i}_{\mathrm{y}}
\end{array}\right]} \\
T_{e}=\frac{3}{2} \frac{p}{2}\left|\Psi_{s}\right| i_{y}
\end{gathered}
$$

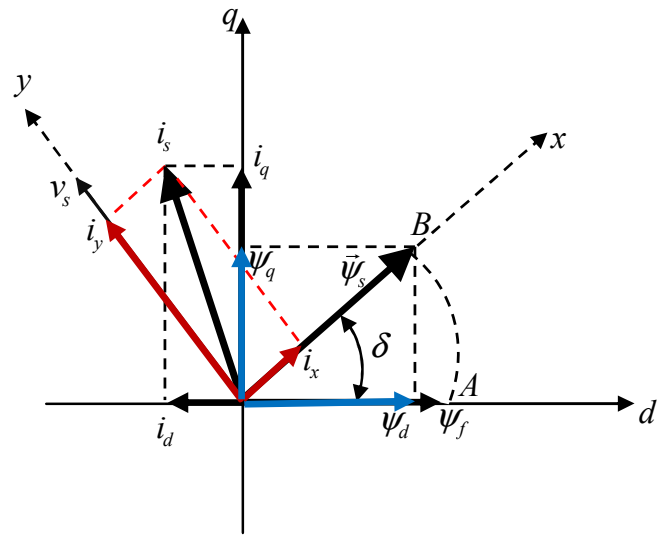

Figure 2. Phase diagram of PMSM in different systems [3]

Based on (9) relation, if flux linkage amount of stator is hold constant, torque will have a direct relation with $y$ components of stator flux and will be controlled with this quantity. As $\Psi_{\mathrm{s}}$ is along with $x$ axe and this vector has no component along with y axe $\left(\Psi_{\mathrm{s}}=0\right)$, therefore by controlling $\mathrm{i}_{x}$, we can easily control the stator flux. To achieve optimized operation PM motor in this method, by controlling stator flux amount, directed state or along with orator flux vector in transient state will be calculated.

In non-salient pole motors (lack of salience), because $\mathrm{L}_{\mathrm{q}}=$ $\mathrm{L}_{\mathrm{d}}$, machine is not able to produce reluctance torque so based on relation (5), current component id has no role in torque production and for achievement to MTPA (maximum torque per Ampere), it is necessary that current equal zero. This cause simplicity of practicing of this control method in these kinds of motors, But in salient pole motor which is $\mathrm{L}_{\mathrm{q}} \neq \mathrm{L}_{\mathrm{d}}$, motor will produce both reluctance and electro mechanic torque and using this method will be a little different. In this mode, torque as a function of current in $\mathrm{d}-\mathrm{q}$ system, is not prolonged to achieve MTPA, it is necessary to calculate minimum distance from in needed torque curve. "Fig. 3" shows a diagram of vector control of PMSM in $\mathrm{x}-\mathrm{y}$ system. $[1,4,5]$

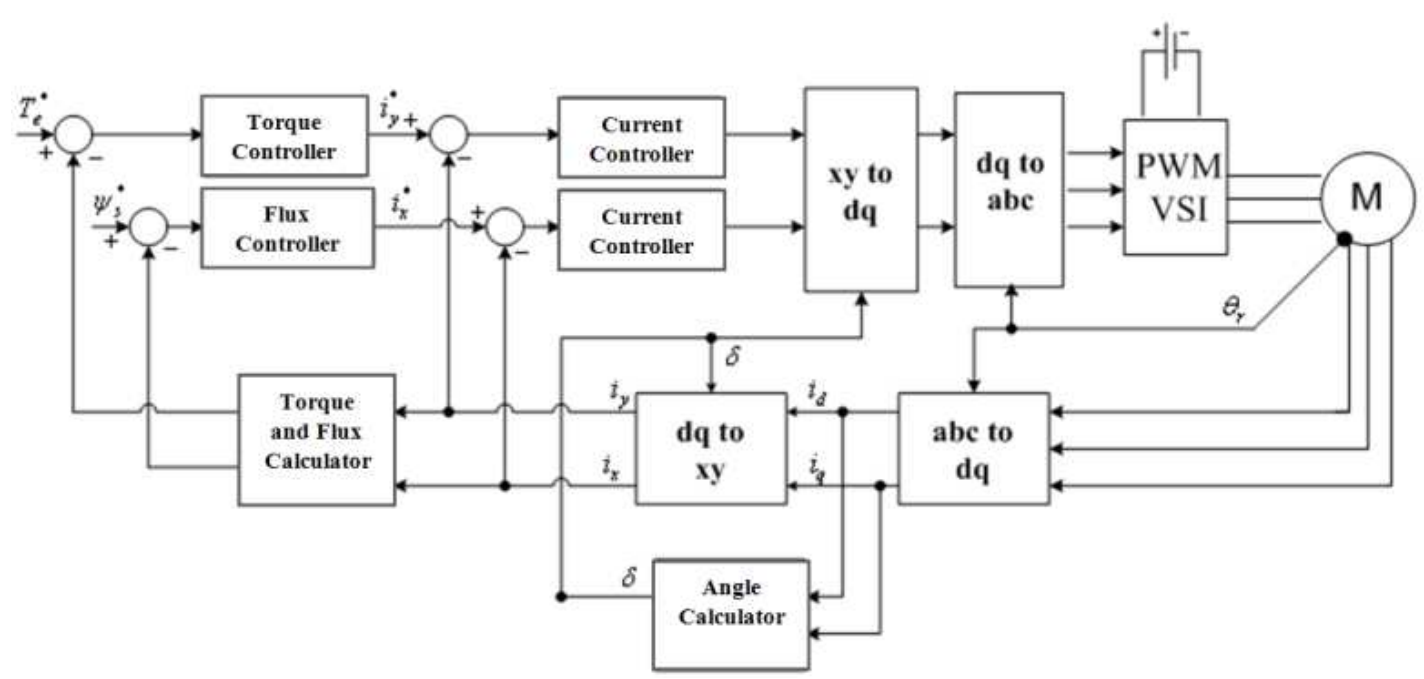

Figure 3. Block diagram of Field-Oriented Control 


\section{Direct Torque Control}

Direct torque control method is one of modern methods to control different kinds of AC motors which is a never method compared to directed flux control method. Basic relation of torque which is a base for practicing this method is defined next.

$$
T_{e}=\frac{3 P}{4 L_{d} L_{q}}\left|\Psi_{s}\right|\left[2 \Psi_{f} L_{q} \sin \delta-\left|\Psi_{s}\right|\left(L_{q}-L_{d}\right) \sin 2 \delta\right]
$$

In this relation, first component of torque is resulted from excitation field and is produced by permanent magnet and second component of torque which is named reluctance torque is because of machine configuration.

By taking a derivative from (10) relation compared to time in the instant $t=o$ (i.e. instant of load variations application), we have:

$$
\left.\frac{d T_{e}}{d t}\right|_{t=0}=\frac{3 P}{2 L_{d} L_{q}}\left|\Psi_{s}\right|\left[\Psi_{f} L_{q} \dot{\delta}-\left|\Psi_{s}\right|\left(L_{q}-L_{d}\right) \dot{\delta}\right]
$$

Which in this relation $\delta$ is angular speed of stator flux linkage with related to permanent magnet flux, round so to achieve a stable torque, following relation should be confirmed:

$$
\left|\Psi_{s}\right|<\frac{L_{q}}{L_{q}-L_{d}} \Psi_{f}
$$

So to have fast dynamic response and fast variation of torque, amount of stator flux linkage should be calculated by using (12) [1].

Usually appoint control command needed to correctly control of flux or torque, hysteresis comparators is used. Hysteresis comparator compares difference between needed amount and evaluated amount and then registers following data for flux and torque vectors.

Torque comparator works in all three levels while flux comparator only works in two levels, because stator flux cannot be held constant during Permanent Magnet Synchronous operation of motor "Fig. 4".

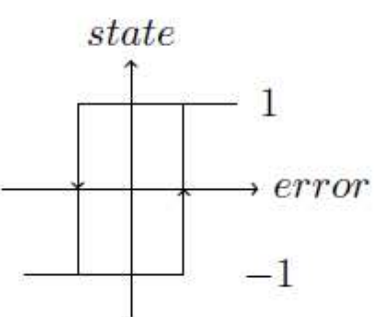

(a) Flux: two level

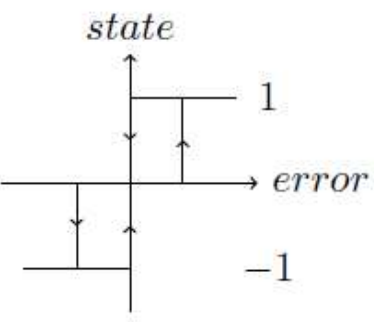

(b) Torque: three level
Figure 4. Hysteresis comparators [6]

By referencing to appointed areas and also by using amounts from table (1), proper voltage vector will be chosen and in this way different states of hysteresis comparator $(\phi, \tau)$ is achieved.

Table 1. Basic table for DTC switching [7]

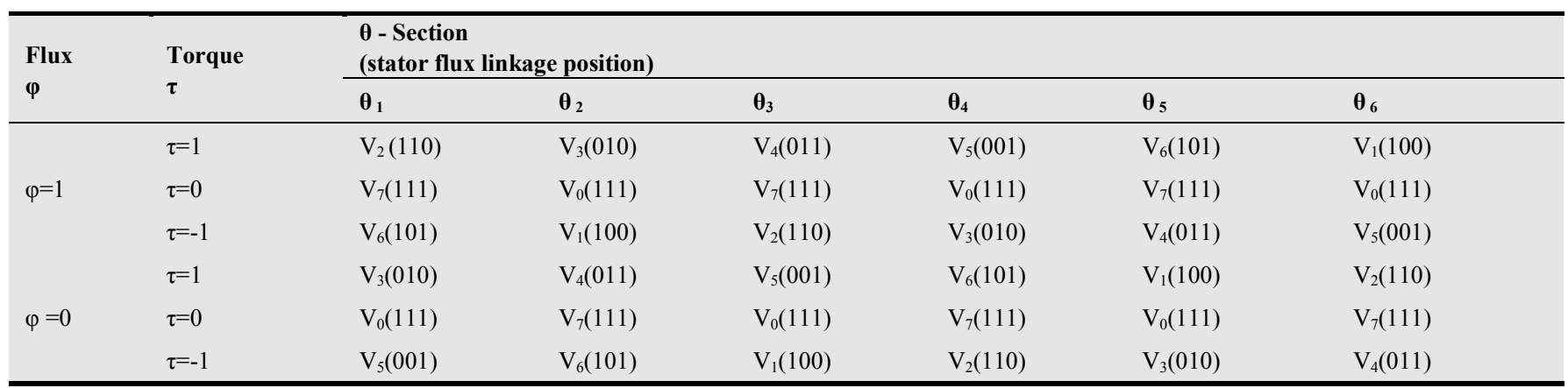

Hysteresis controllers of flux and torque give proper output based on difference between evaluated amount and command amount of flux and torque.

If $\phi=1$, this means that real amount of stator flux linkage is lower than reference amount of flux. If $\phi=0$, so real amount of stator flux linkage is higher than reference amount of flux. If $\tau=1$, real amount of electromagnetic torque is lower than command torque and so torque should have a raise, therefore by application of proper voltage vector and by raising angle $\delta$, torque will increase. If $\tau=-1$, so real amount torque is higher than reference torque amount.

To decrease ripple of torque, instead of two levels of torque decrease and increase, state of "no change" can be added which means $\tau=0$. This can be done by application of zero voltage vectors. This is shown in table (1) $[2,3,8]$

Six switches three phase voltage source inverter in this control method can be seen in "Fig. 5". This inverter creates six non-zero voltage vectors and two zero voltage vectors (totally eight vector $\mathrm{V}_{0} \cdot \mathrm{V}_{1}, \mathrm{~V}_{2}, \mathrm{~V}_{3} \cdot \mathrm{V}_{4} \cdot \mathrm{V}_{5}, \mathrm{~V}_{6} \cdot \mathrm{V}_{7}$ )

In switching time, voltage vector will be constant and stator resistance will also be supposed constant. In relation (13), $\left.\Psi_{\mathrm{s}}\right|_{\mathrm{t}=o}$ is preliminary amount of stator flux linkage in the beginning of switching. By ignoring stator resistance, relation between stator flux linkage and voltage is described as following:

$$
\Psi_{s}=v_{s} t+\left.\Psi_{s}\right|_{t=0}=>\Delta \Psi_{s}=v_{s}
$$



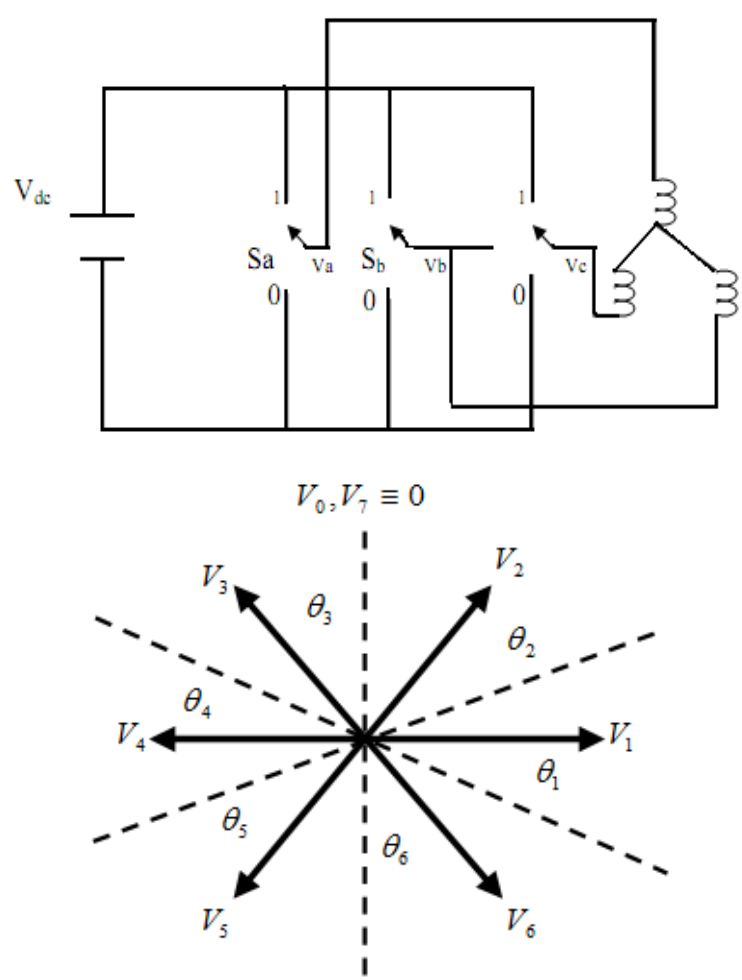

Figure 5. Schematic of inverter and voltage vectors presentation in DTC [9]
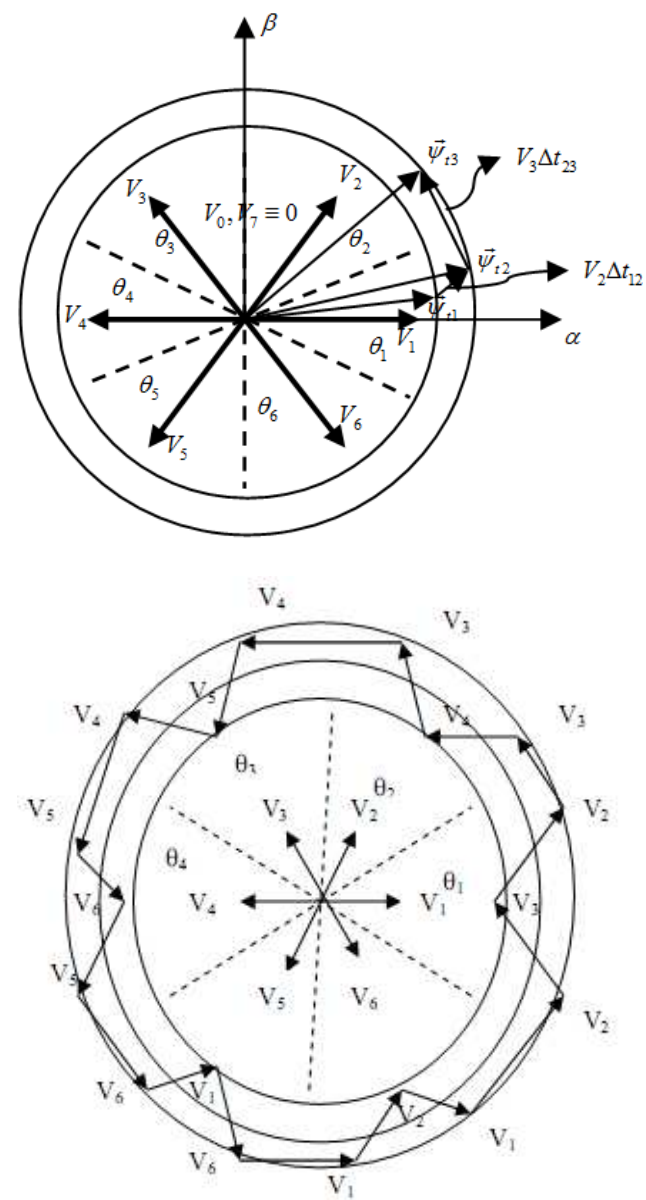

Figure 6. Rotation of stator flux linkage vector by voltage vector [9]
Based on relation (13), movement of stator flux linkage is coordinated with application voltage to stator "Fig. 6". So amount, movement way and movement speed of stator flux linkage can be controlled by choosing proper voltage vector.

In each six- fold area, to decrease or increase or increase stator flux amount, two voltage vectors will be chosen which result in lower switching frequency. Therefore if zero voltage is applicator to machine, vector $\Psi$ s will stay in its right place. In permanent magnet synchronous motor, stator flux linkage will be achieved by mixture stator voltage and rotor magnetic flux vectors. As permanent magnet flux is rotating all the time. Even if zero voltage is used, there is stator flux- round so using zero voltage just decreases the torque.

Therefore inverse voltage vector is usually used to decrease torque fast and zero voltage vectors are not used to control stator flux- round so stator flux vector $\Psi_{\mathrm{s}}$ is always moving related to rotor flux linkage.

As relation (10) shows, electromagnetic torque can be effectively controlled by controlling stator flux linkage amount and its rotation speed. For anti-clockwise operation, if real torque is lower than reference torque, voltage vector are chosen so as cause rotation of $\Psi_{\mathrm{s}}$ in the same direction (triangular).

In this state, angle $\delta$ changes fast and real torque of machine will increase. If motor torque is higher than reference amount, voltage vector will be chosen so as cause rotation of $\Psi_{\mathrm{s}}$ in inverse direction and so $\delta$ and torque decrease.

Table (1) is for controlling amount and rotation direction of vector $\Psi$ s which is used for both operation ways. In this table, $\tau$ and $\phi$ are outputs of hysteresis flux and torque controllers respectively, and $\theta_{1}-\theta_{6}$ show area of space vector page in which stator flux- round vector is placed. This table shows DTC control strategy for IPM motor $[9,10]$

\section{Study and Comparison FOC and DTC}

In table (2), two control methods for FOC and DTC are compared with 5 basic indices. So with respect to aforementioned table, practicing direct control of torque is very simpler than directed flux control therefore it is preferred. From above comparison on I (we) conclude, in spite of that both these methods are in control vector group, but they have very external differences. So it seems that these two methods basically have no common point. Simulation results show this very well.

Table 2. Comparison of FOC and DTC

\begin{tabular}{|c|c|c|}
\hline Index Method & FOC & DTC \\
\hline System Transformation & need & no need \\
\hline Voltage Modulation & need & no need \\
\hline Calculation Value & high & low \\
\hline Sensivity To Parameter Changes & yes & no \\
\hline Sensor Position & need & no need \\
\hline
\end{tabular}

\section{Simulation Results}

In this section, system of Field-Oriented Control and Direct 
Torque Control in permanent magnet synchronous motor is simulated. Simulation parameters of studied motor have been shown in table (3).

Output specifications of two control system should be compared with each other in the same operational conditions. In the following, results of two systems simulation, creator factors and finally similarities and differences of these two systems will be studied.

Table 3. PMS motor parameters

\begin{tabular}{ll}
\hline Parameter & value \\
\hline $\mathrm{P}$ & 6 \\
$\mathrm{R}$ & $4.1 \Omega$ \\
$\mathrm{Ld}$ & $.0511 \mathrm{H}$ \\
$\mathrm{Lq}$ & $.066 \mathrm{H}$ \\
$\varphi \mathrm{f}$ & $.154 \mathrm{~Wb}$ \\
$\omega \mathrm{b}$ & $1000 \mathrm{rpm}$ \\
$\mathrm{V}$ & $350 \mathrm{~V}$ \\
\hline
\end{tabular}

Figure 7 and 8 show machine torque variations in terms of time for two control methods. At first starting torque increases, after arriving a specified speed, torque profile will have stable swings around a zero. Based on achieved results, we can conclude that machine response to load torque variations in DTC method is a little less than FOC method.
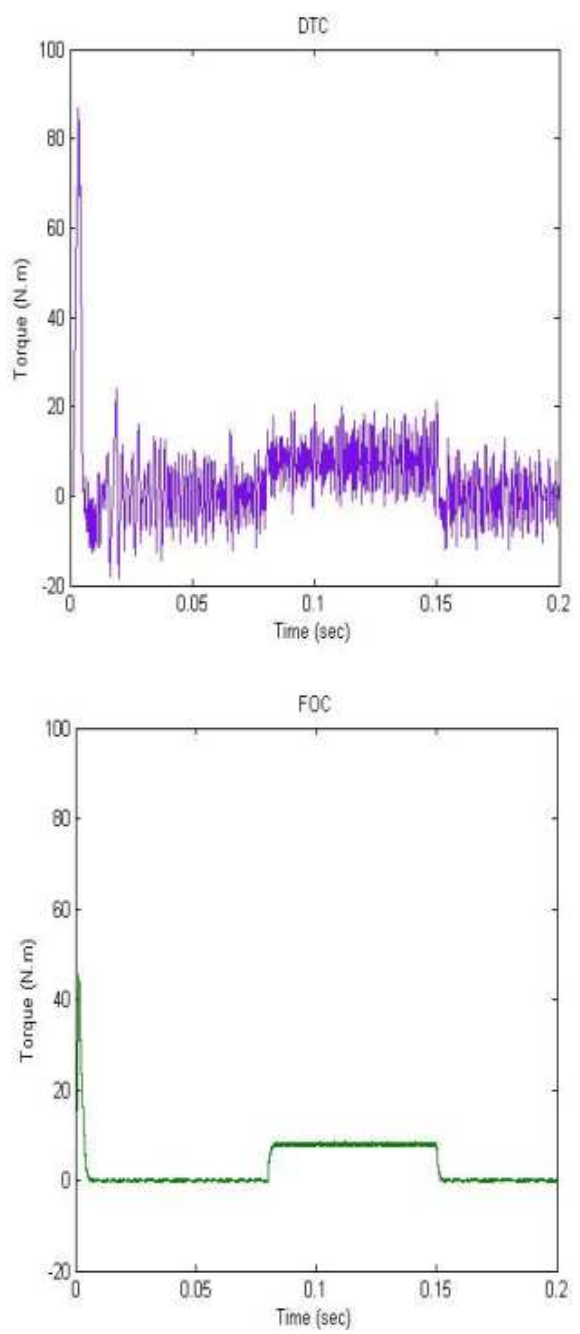

Figure 7. Torque variations in rated speed
It is seen that torque swig in DTC method is much more compared to FOC method. This is because of torque hysteresis controller in DTC method and its direct effect on machine torque.

"Fig. 8" shows torque variation diagram presented in "Fig. 7 "in a smaller time range. This waveform shows high torque ripple in DTC method compared to its low swing in FOC method.
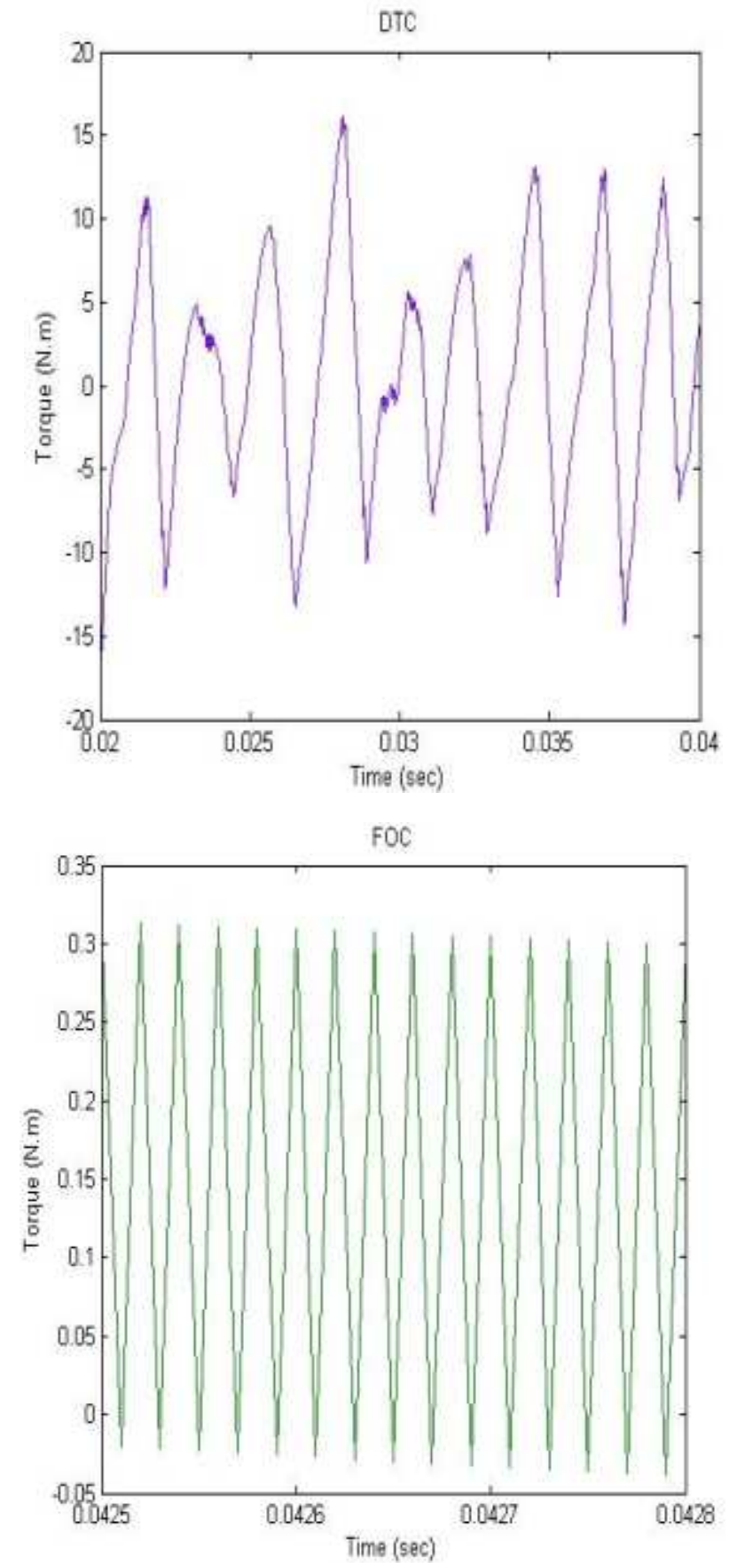

Figure 8. Fine torque variations

Figure 9 shows a motor three phases current diagram in rated speed when full load is applied to machine, current waveform in DTC method have more disorder than FOC method, which is because of hysteresis controllers is in DTC method. 

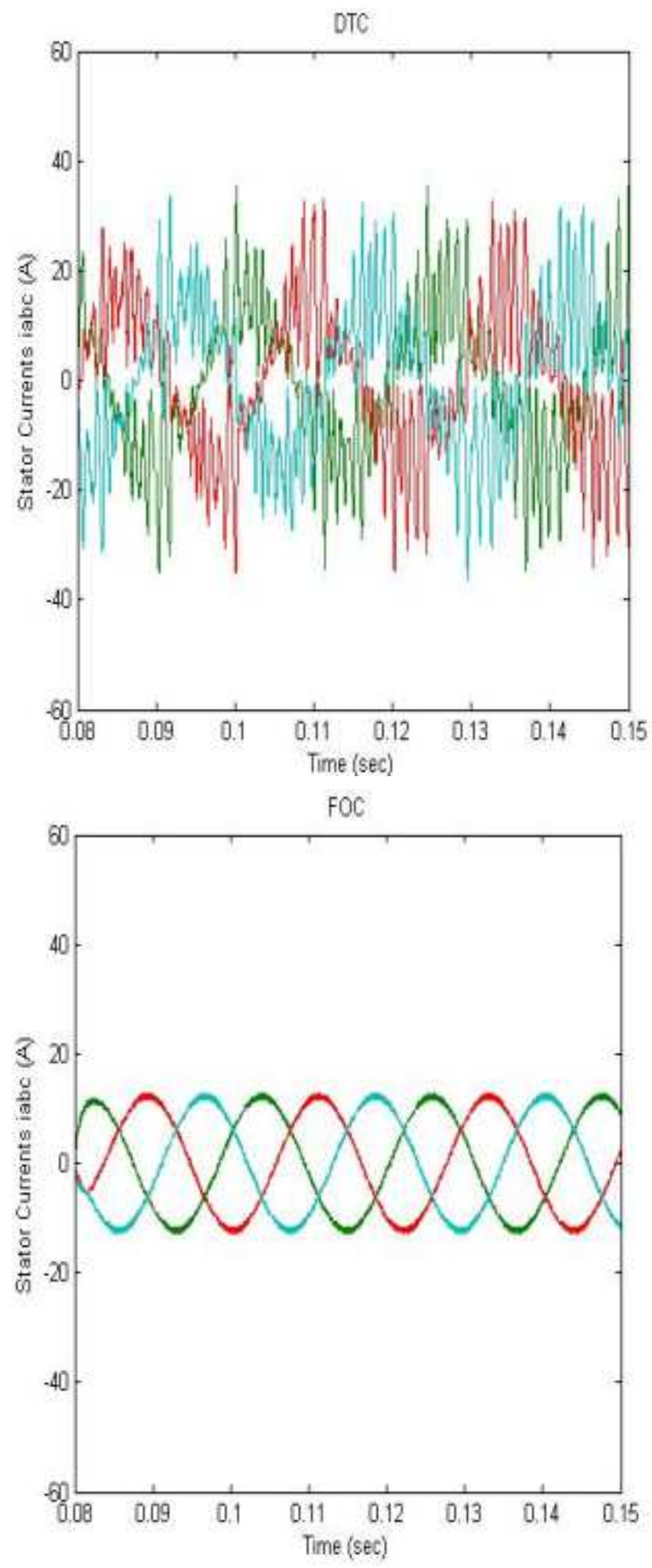

Figure 9. Stator three phase's current diagram in full

Furthermore, Figure 10 shows pick of phase current in a small time range. Current swing in DTC method is more than FOC method and this swing even become more in low load. Existence of many swings in current waveform in DTC method is one the great disadvantages of this method compared to FOC method.
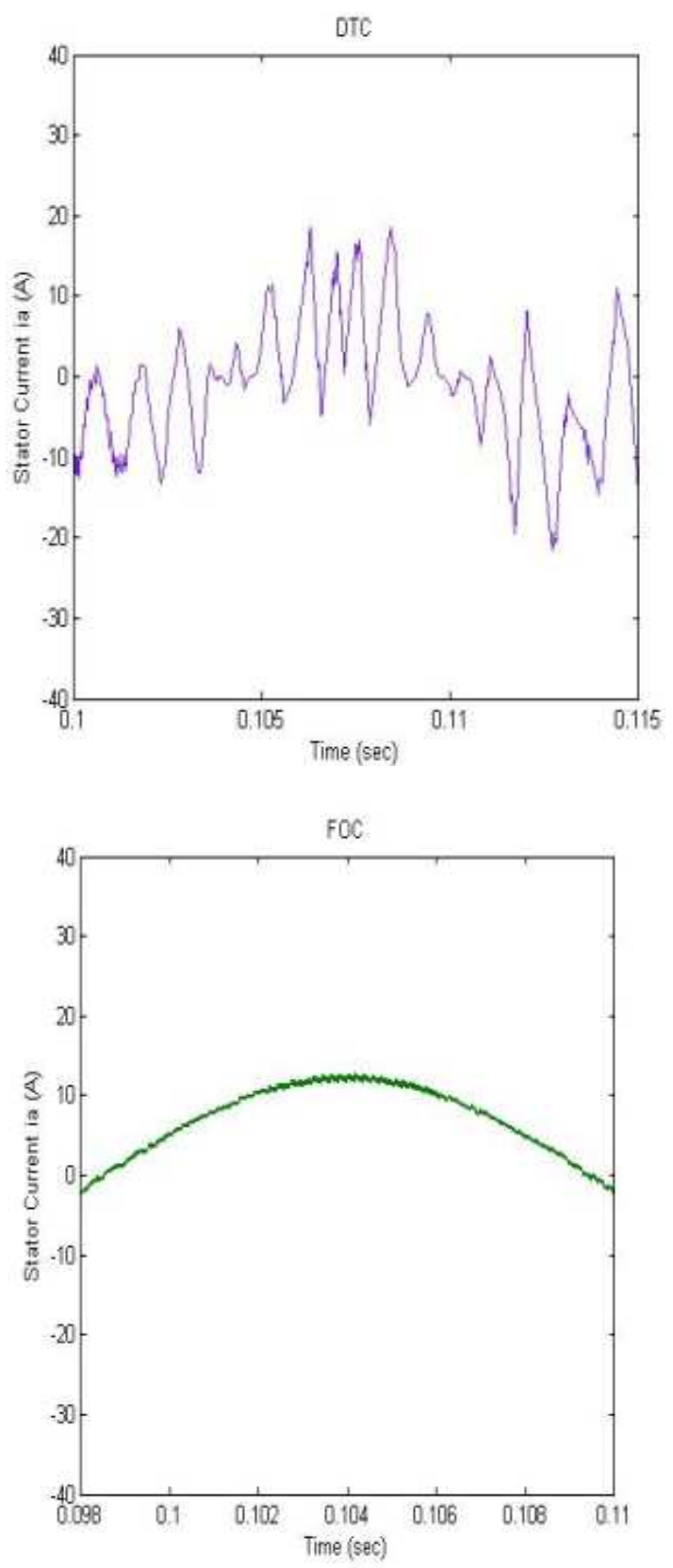

Figure 10. Pick of phase current in full load in both methods

Figure 11 and 12 shows stator flux variations in terms of time in rated speed from no load to full load. In both method control method, amount of command flux will be considered 0.29 Weber (almost two times of permanent magnetic flux of rotor).

A desired control system is a system that its flux stays constant by applied load torque to machine and is not affected by distortion. Figure 11 shows that in both control methods it is satisfied and by applying load torque, motor flux has stayed constant.

As it is seen in Figure 12, in DTC method, because of existence of flux hysteresis controller and its effects on flux, created ripple is much more than FOC method. In DTC method, this ripple amount is equal to width of flux hysteresis band. 

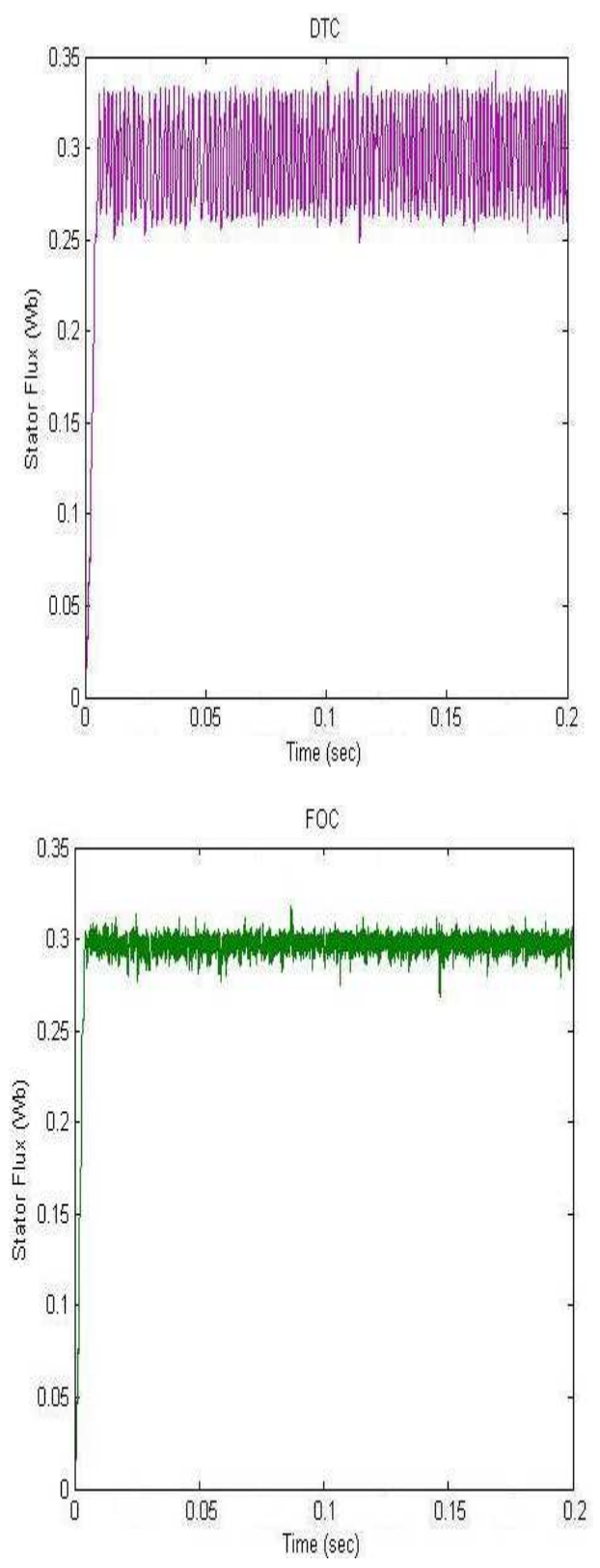

Figure 11. Stator flux variations diagram
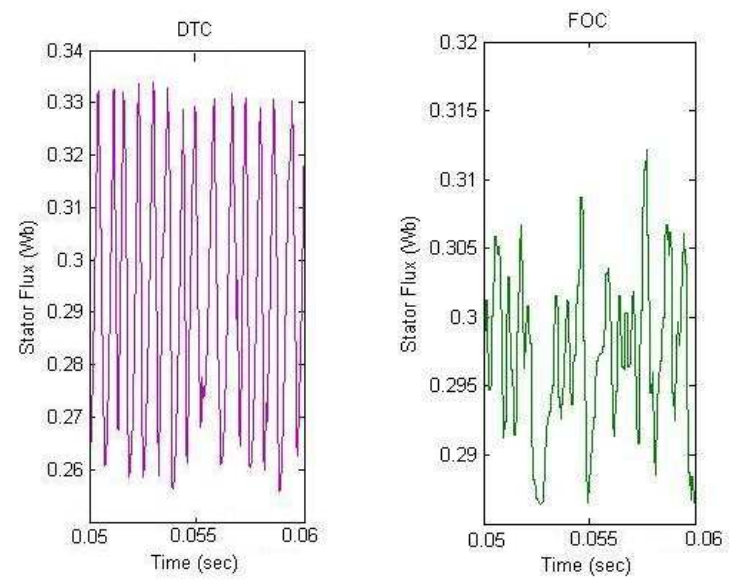

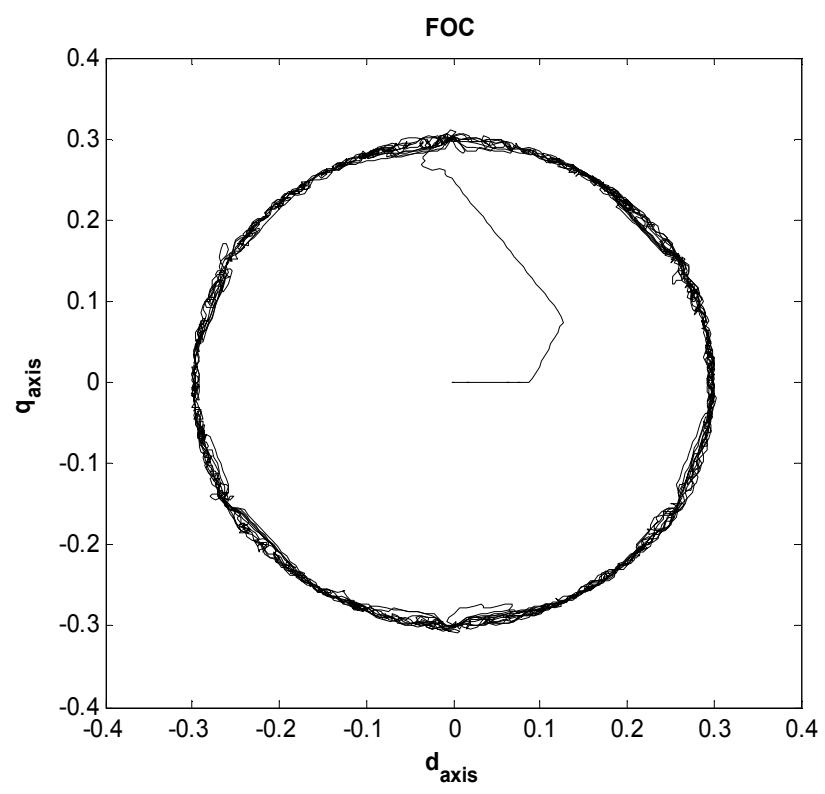

(a)

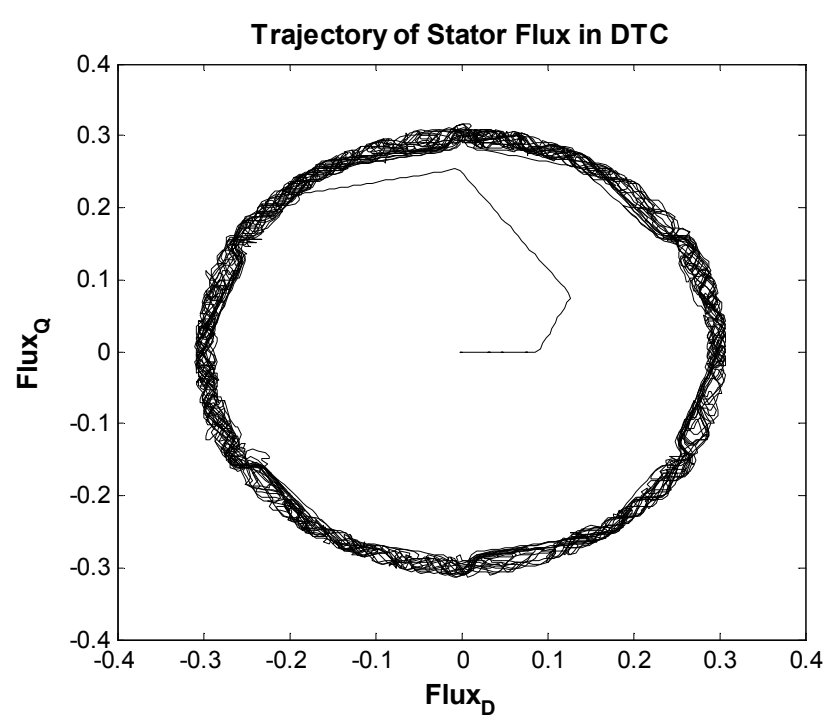

(b)

Figure 13. Stator flux vector direction presentation diagram

Figure 13.a and 13.b show movement direction of stator flux vector in DTC and FOC methods. These two diagrams are almost same, by this difference that flux diagram in FOC method get its desired amount a little faster, but flux ripple in DTC method is more. Reason of faster flux in FOC method can be considered flux direction finding along with stator flux. As before mentioned, reason of more ripples in DTC is existence of hysteresis flux controller.

Figure 14 shows Speed variations diagram for two control method. Observation, in DTC method we achieve early as possible to the response.

Figure 12. Flux variation waveform in both case control methods. 

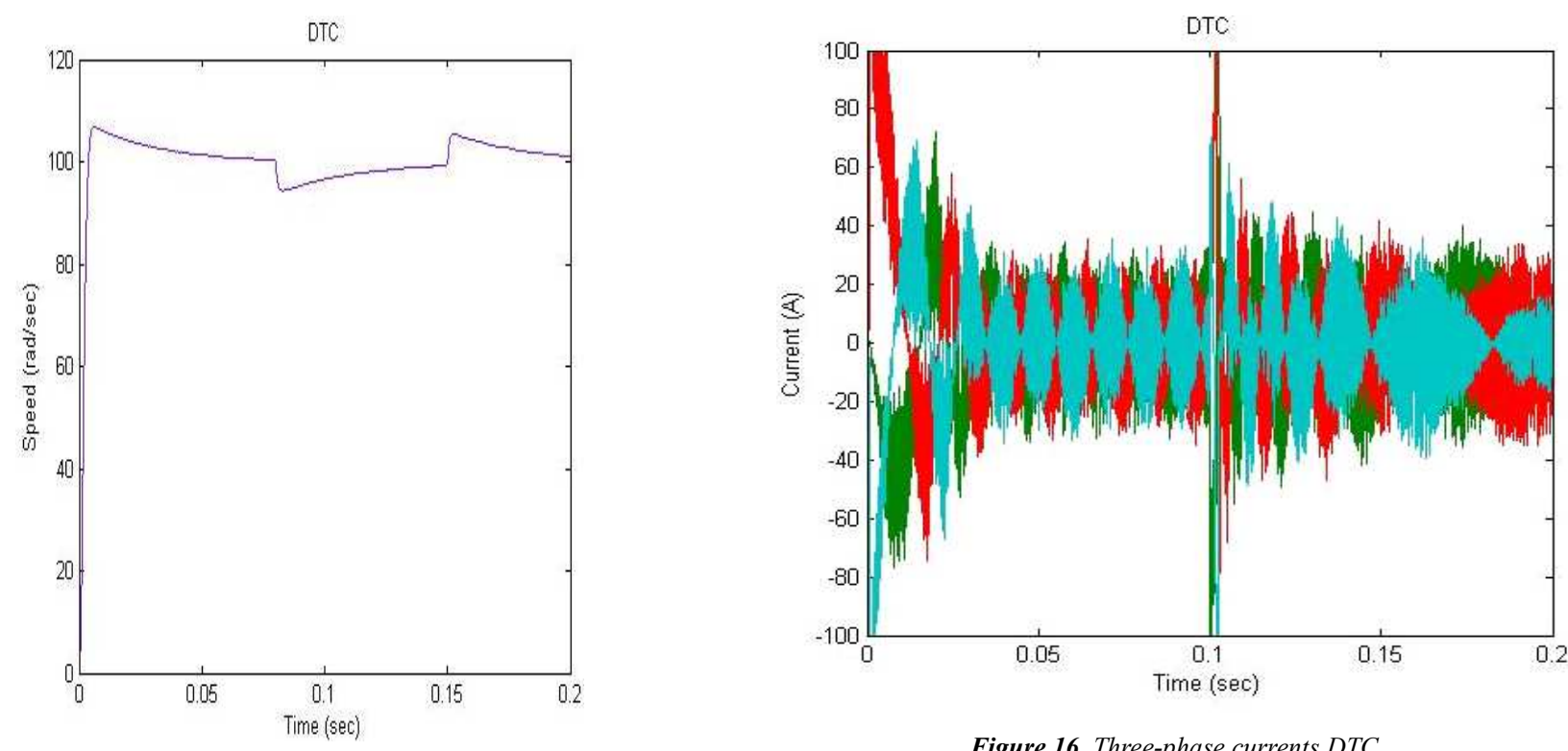

Figure 16. Three-phase currents DTC
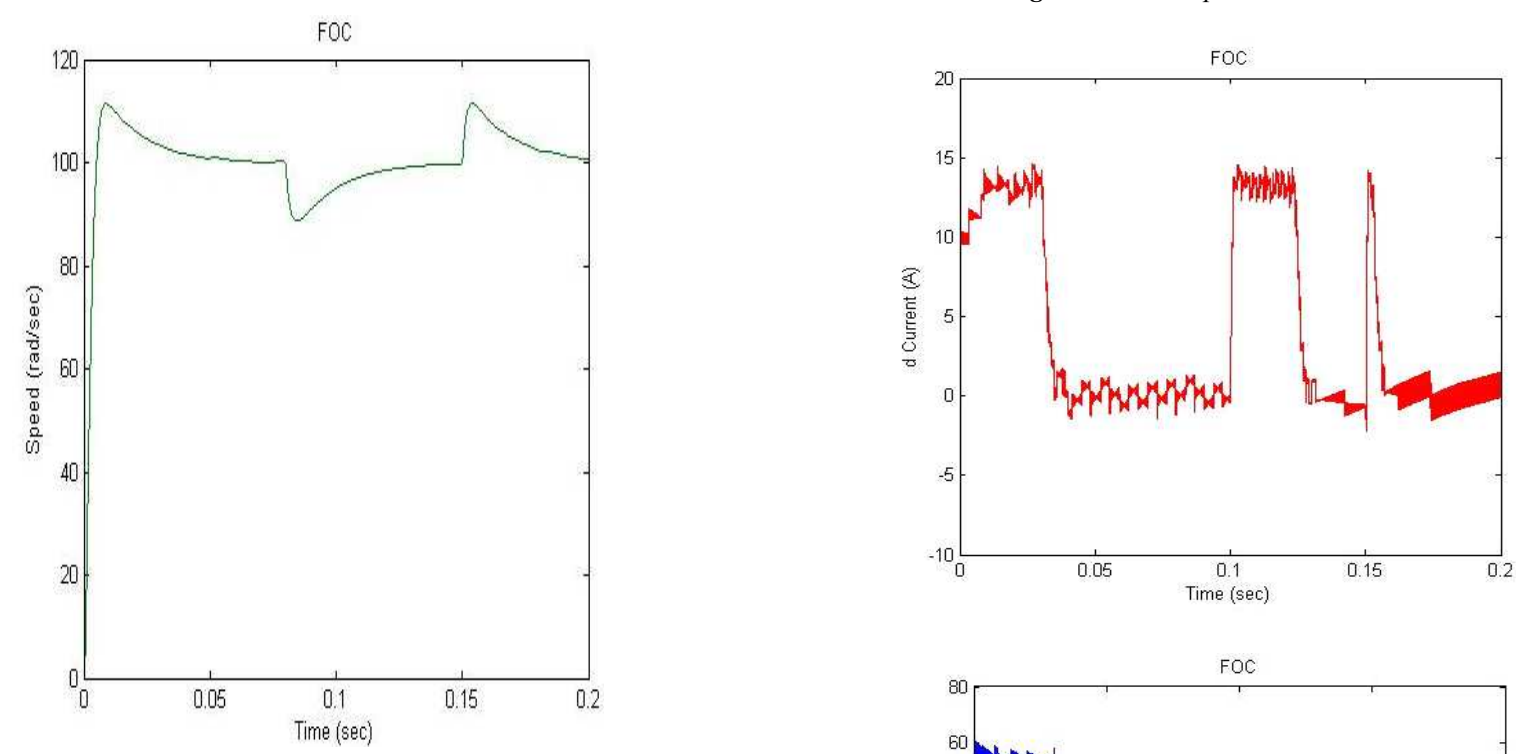

Figure 14. Speed variations diagram

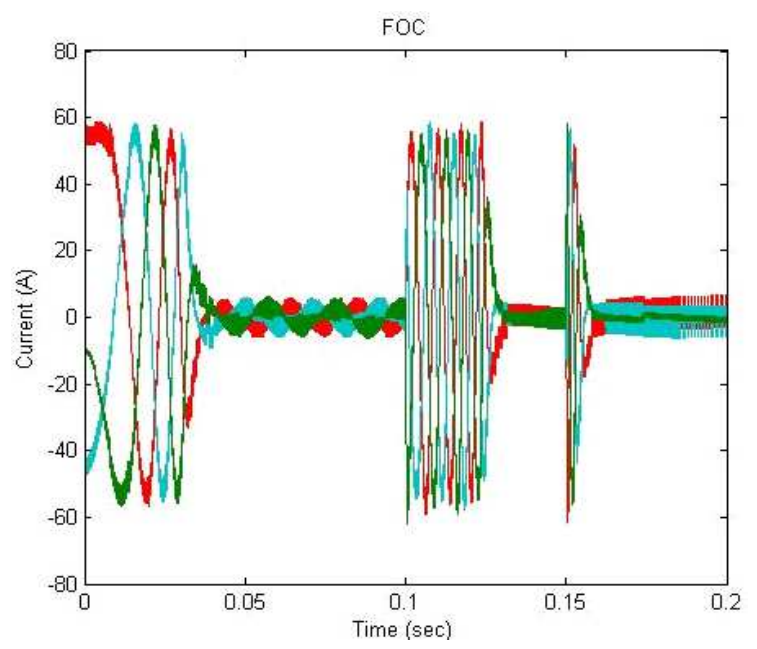

Figure 15. Three-phase currents FOC

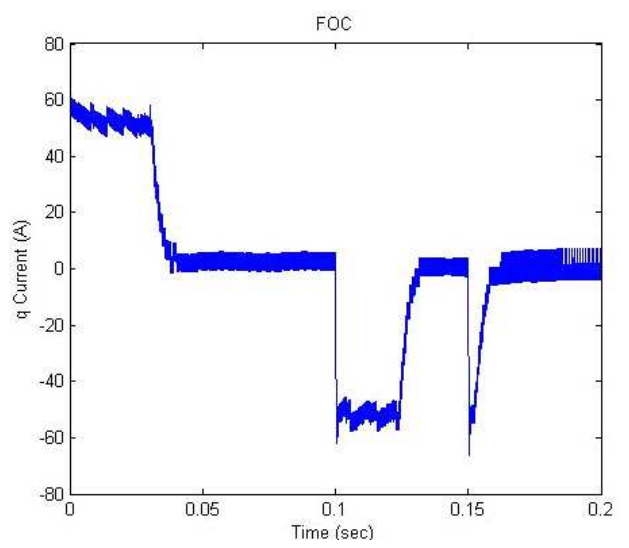

Figure 17. The longitudinal and transverse axes $(d-q)$ in the FOC approach

Figure 15 and 16, the phase currents for the two methods show FOC and DTC are approximately the difference between the two methods can be observed. Flow chart of the method of phase FOC as its torque curve method is formed around zero, while the method DTC phase currents are relatively higher than zero. The reason for this behavior is that the DTC method. Unlike methods that FOC, the direct control of the $d$ axis currents and q does not exist. 
These issue forms Figure 17 and 18 can be seen. Also Three-phase current waveforms DTC compared to the FOC is having ripple and high volatility, which hysteresis in DTC method is used because it controls.
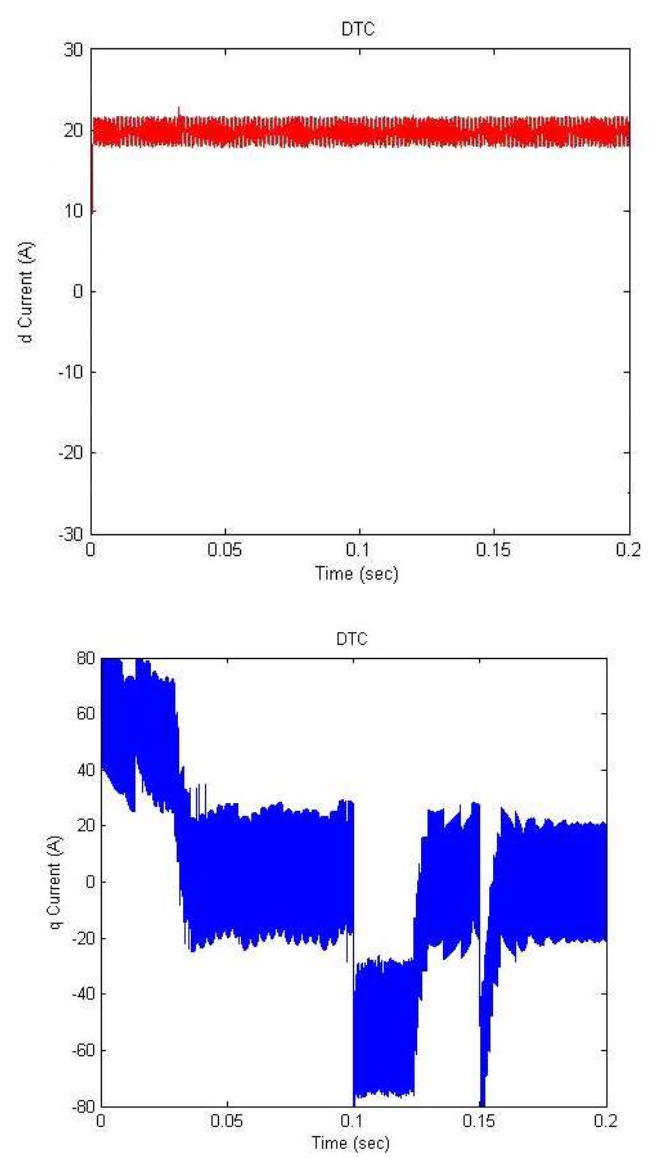

Figure 18. The longitudinal and transverse axes (d-q) DTC

\section{Discussion and Conclusion}

In this paper, two common control methods including FOC and DTC of the PMS motor is discussed in detail. The main characteristics of the motor such as torque, flux and speed under different operation conditions studied and the advantages of FOC and DTC are obtained. It can be concluded that although both the DTC and FOC methods have different implementation structures but the motor has the same behavior on the control methods. Therefore, it is deduced that both the methods can be named as direct flux control and can be applied as an optimized method to substitute custom control methods of these kinds of motors in the industry applications.

\section{References}

[1] Juha Pyrhonen. 2011, ELECTRIC-DRIVE-BASED CONTROL AND ELECTRIC ENERGY REGENERATION IN A HYDRAULIC SYSTEM.Book..

[2] P. Pragasan, and R. Krishnan, 1998, Modeling of permanent magnet motor drives, IEEE Trans. Industrial electronics, vol. 35 , no.4, nov. $1988 \backslash$

[3] Anders Kornberg, 2012, Design and Simulation of Field Oriented Control and Direct Torque Control for a Permanent Magnet Synchronous Motor with Positive Saliency.Thesis For M.S. degree ,uppsala university.

[4] Thomas M. Jahns, Gerald B. Kliman, and Thomas W. Neumann. Interior permanent-magnet synchronous motors for adjustable-speed drives. IEEE Transaction on industry applications, IA-22(4):738-747, 1986.

[5] R.D. Doncker, D.W.J. Pulle, and A. Veltman. Advanced Electrical Drives: Analysis, Modeling, Control. Power Systems. Springer, 2011. ISBN 9789400701793. URLhttp://books.google.se/books?id=\_sEDx21AKboC.

[6] Yi Wang and Jianguo Zhu. Modeling and implementation of an improved dsvm scheme for pmsm dtc. International Conference on Electrical Machines and Systems, pages 1042-1046, 2008.

[7] H. L. Huy, 1999, Comparison of Field-Oriented Control and Direct Torque Control for Induction Motor Drives, 0-7803-5589-X/99/10.00 @ 1999 IEEE.

[8] [8] A. Daghigh, M.B.B. Sharifian, M. Farasat, A Modified Direct Torque Control of IPM Synchronous Machine Drive With Constant Switching Frequency and Low Ripple in Torque, in Conf. 18th Iranian conference on Electrical Engineering, ICEE, Isfahan-Iran, 2010.

[9] L. Zhong, M. F. Rahman, 1997, Analysis of Direct Torque Control in Permanent Magnet Synchronous Motor Drives, IEEE TRANSACTIONS ON POWER ELECTRONICS, VOL. 12, NO. 3, MAY 1997

[10] L. Zhong, M. F. Rahman, and K. W. Lim, 1995, A strategy for torque control for high-performance interior permanent magnet synchronous motor drives, in Proc. Australasian Univ. Power Engineering Conf., 1995, pp. 259-264. 